Short Communication

\title{
Particle size distributions and gas-particle partitioning of polychlorinated dibenzo-p-dioxins and dibenzofurans in ambient air during haze days and normal days
}

\author{
Xian Zhang a,b, Minghui Zheng a,c,*, Yong Liang ${ }^{\text {c }}$, Guorui Liu ${ }^{\text {a }}$, Qingqing Zhu ${ }^{\text {a,b }}$, Lirong Gao a ${ }^{\text {a }}$ Wenbin Liu ${ }^{\text {a }}$, \\ Ke Xiao ${ }^{a}$, Xu Sun ${ }^{d}$

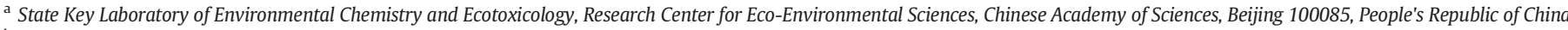 \\ ${ }^{\mathrm{b}}$ University of Chinese Academy of Sciences, Beijing 100049, People's Republic of China \\ ${ }^{\mathrm{c}}$ Institute of Environment and Health, Jianghan University, Wuhan 430056, People's Republic of China \\ d Beijing Urban Ecosystem Research Station, Research Center for Eco-Environmental Sciences, Chinese Academy of Sciences, Beijing 100085, People's Republic of China
}

\section{H I G H L I G H T S}

- $\mathrm{PCDD} / \mathrm{F}$ particle size distributions on haze days and normal days were determined.

- Higher concentrations of airborne PCDD/Fs were detected during all haze days.

- $95 \%$ of PCDD/Fs were absorbed in the $d_{a e}<2.5 \mu \mathrm{m}$ particles on haze days.

- Harner-Bidleman model predicted the particulate fractions of PCDD/F congeners well.

\section{G R A P H I C A L A B S T R A C T}
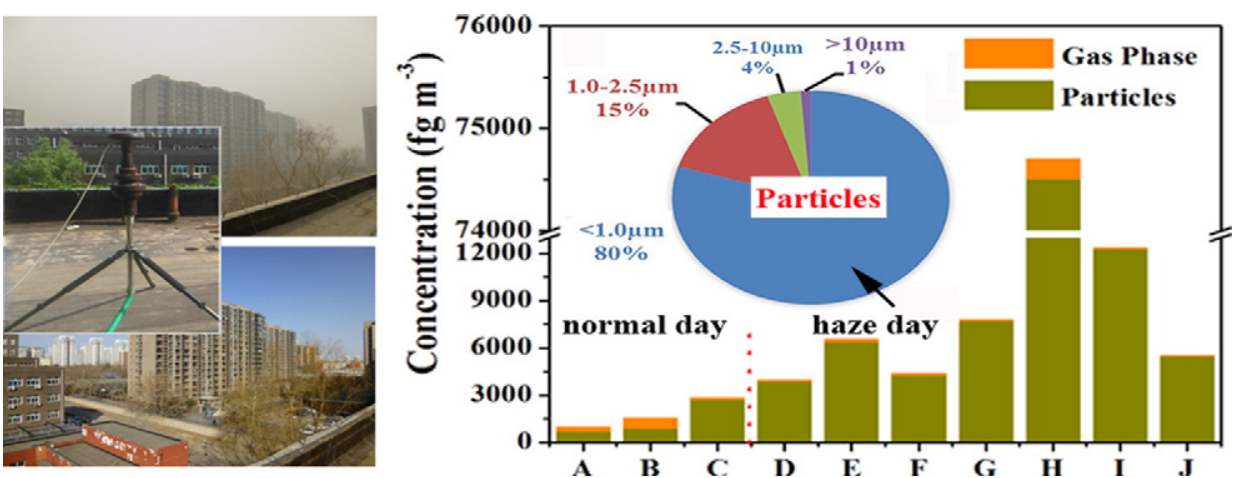

The following figure is presented as the graphical abstract.

\begin{abstract}
A B S T R A C T
Little information is available on the distributions of airborne polychlorinated dibenzo-p-dioxins and dibenzofurans $(\mathrm{PCDD} / \mathrm{Fs})$ during haze days. In this study, $\mathrm{PCDD} / \mathrm{F}$ concentrations, particle size distributions, and gas-particle partitioning in a Beijing suburban area during haze days and normal days were investigated. High PCDD/F concentrations, 3979-74,702 $\mathrm{fg} \mathrm{m}^{-3}$ (173-3885 fg I-TEQ $\mathrm{m}^{-3}$ ), were found during haze days and $\sim 98 \%$ of the $\mathrm{PCDD} / \mathrm{Fs}$ were associated with particles. Most PCDD/F congeners (>90\%) were associated with particles. PCDD/ F concentrations increased as particle sizes decreased and 95\% of the particle-bound PCDD/Fs were associated with inhalable fine particles with aerodynamic diameters $<2.5 \mu \mathrm{m}$. PCDD/Fs were mainly absorbed in the particles and the Harner-Bidleman model predicted the particulate fractions of the PCDD/F congeners in the air samples well. The investigated PCDD/F concentrations and particle-bound distributions were different during normal days than during haze days. Temporal airborne PCDD/F trends in a suburban area during haze conditions could support better understanding of the exposure risk posed by toxic PCDD/Fs associated with fine particles.
\end{abstract}

(C) 2016 Elsevier B.V. All rights reserved.

\footnotetext{
* Corresponding author at: State Key Laboratory of Environmental Chemistry and Ecotoxicology, Research Center for Eco-Environmental Sciences, Chinese Academy of Sciences, Beijing 100085, People's Republic of China.
}

E-mail address: zhengmh@rcees.ac.cn (M. Zheng). 


\section{Introduction}

Polychlorinated dibenzo-p-dioxins and dibenzofurans (PCDD/Fs) are well-known, unintentionally produced, toxic halogenated aromatic hydrocarbons that are formed and released during thermal and chemical processes (Fiedler et al., 1990). PCDD/Fs are ubiquitous in the environment and tend to be environmentally persistent, bioaccumulate in lipids in biota, and undergo long-range transport (Ssebugere et al., 2014b). Long-term exposure to PCDD/Fs can severely affect the human immune and reproductive systems, and increase adverse attention-related behaviors (Neugebauer et al., 2015; Schecter et al., 2006). The sources and fates of PCDD/Fs need to be studied in more detail to allow PCDD/F exposure risks to humans to be better understood and managed.

Although some studies on the concentrations and environmental behaviors of PCDD/Fs in ambient air have been carried out (Chandra Suryani et al., 2015; Vilavert et al., 2014), less attention has focused on $\mathrm{PCDD} / \mathrm{Fs}$ in ambient air in comparison to PCDD/F emissions from industrial sources (Balasubramani and Rifai, 2015; Liu et al., 2009; Tang et al., 2013). PCDD/Fs can be transported around the world in the atmosphere. PCDD/Fs usually show clear gas-particle partitioning and mainly partition to particles (Lee and Jones, 1999; Li et al., 2008; Lohmann et al., 2000). The sizes of suspended particles influence the distribution of airborne PCDD/Fs more than temperature and humidity (Correa et al., 2004; Martínez et al., 2006). Some studies of PCDD/F distributions in particles with different sizes have been reported and PCDD/Fs were found to preferentially distribute in fine particles (Chao et al., 2003; Degrendele et al., 2014; Kaupp and McLachlan, 2000; Oh et al., 2002; Zhang et al., 2015). For example, $60 \%$ of PCDD/Fs were found in particles with aerodynamic diameter $\left(d_{\mathrm{ae}}\right)<0.41 \mu \mathrm{m}$ (Oh et al., 2002) and $80 \%$ of PCDD/Fs were associated with particles with $d_{\mathrm{ae}}<1.0 \mu \mathrm{m}$ (Zhang et al., 2015). Lower chlorinated PCDD/Fs are preferentially distributed in coarse particles and higher chlorinated PCDD/Fs are associated with fine particles. The concentration, gas-particle partitioning and particle size distributions of PCDD/Fs can vary greatly during extreme conditions. For example, PCDD/F concentrations were found to increase more than fine particle concentrations during haze days (In and Park, 2003; Ohta et al., 2002). However, limited data on PCDD/F distributions during different weather conditions, such as rainy and haze days, have been reported (Chi et al., 2009; Hung et al., 2002; Thuan et al., 2013; Zhou et al., 2014). Recently, haze has occurred more frequently in many of China's main cities. To the best of our knowledge, there have been no studies on particle size distributions of ambient airborne $\mathrm{PCDD} /$ Fs during haze days. This is a significant oversight because this information is important for improving our understanding of PCDD/F distributions in haze.

In this study, $\mathrm{PCDD} / \mathrm{F}$ concentrations, particle size distributions and gas-particle partitioning during haze days and normal days in a Beijing suburban area were investigated and the different results found during haze days and normal days were explored.

\section{Methods and materials}

\subsection{Sample collection}

Size-segregated particulate matter $\left(d_{\mathrm{ae}} \mathrm{s}>10,2.5-10,1.0-2.5\right.$, and $<1.0 \mu \mathrm{m}$ ) and gas phase samples were collected at the Beijing urban ecosystem research station $\left(116.34^{\circ} \mathrm{E}, 40.01^{\circ} \mathrm{N}\right)$. In this study, days when $\mathrm{PM}_{1.0}$ concentrations were $<100 \mu \mathrm{g} \mathrm{m}^{-3}$ and visibility (Lin et al., 2014) was $>10 \mathrm{~km}$ were defined as normal days, and days when $\mathrm{PM}_{1.0}$ concentrations were $>100 \mu \mathrm{g} \mathrm{m}^{-3}$ and visibility was $<10 \mathrm{~km}$ were classified as haze days. Three normal day samples, labeled as samples A, B and C, were collected.

between 1 July and 14 August 2014 and seven haze day samples were collected between 12 September and 11 November 2014 (labeled as samples D, E, F, G, H, I and J). Each sample was collected with the sampling duration of 7 days for normal days and 4 days for haze days. The samples were collected using a KS-303 PM PM/2.5/1.0 $_{\text {sampler }}$ (Kálmán, Budapest, Hungary) on the roof of a $12 \mathrm{~m}$ tall building. The sampling flow rate was $400 \mathrm{~L} \mathrm{~min}^{-1}$. More detailed sampling information and descriptions of the filter pretreatments and sample treatments are provided in the Supporting information (SI).

\subsection{Sample analysis}

The samples were analyzed for 17 2,3,7,8-substituted PCDD/Fs following US Environmental Protection Agency method 1613B. Briefly, each quartz fiber filter and PUF was spiked with a surrogate standard solution, prepared from mixture EPA-1613LCS (Wellington Laboratories, Guelph, Canada), containing 1 ng of each ${ }^{13} \mathrm{C}_{12}$-labeled surrogate standard PCDD/F. Each was then extracted with a 1:1 dichloromethane and hexane mixture. Each extract was concentrated and transferred into pure hexane, then cleaned by passing it through, successively, a multilayer silica gel column, a basic alumina column, and an activated carbon column. The clean extract was concentrated and transferred into $10 \mu \mathrm{L}$ nonane, to which $1 \mathrm{ng}$ of the ${ }^{13} \mathrm{C}_{12}$-labeled injection standard (EPA-1613 IS; Wellington Laboratories) was added.

An Agilent 6890 high-resolution gas chromatograph (Agilent Technologies, Santa Clara, CA, USA) coupled to an Autospec Ultima high-resolution mass spectrometer (Waters, Milford, MA, USA) with an electron impact (EI) ion source was used to determine PCDD/Fs in the extracts. The gas chromatograph was fitted with a DB-5 MS column (60 m long, $0.25 \mathrm{~mm}$ inside diameter, $0.25 \mu \mathrm{m}$ film thickness; Agilent Technologies). The mass spectrometer was operated in selected ion monitoring mode at a resolution $>10,000$. Helium served as the carrier gas with a constant flow of $1.0 \mathrm{~mL} \mathrm{~min}^{-1}$. The election emission energy was set at $35 \mathrm{eV}$, and the source and transmission line temperatures were $270{ }^{\circ} \mathrm{C}$ and $280{ }^{\circ} \mathrm{C}$, respectively. The GC oven temperature program was set as follows: $160{ }^{\circ} \mathrm{C}, 2 \mathrm{~min}, 7.5^{\circ} \mathrm{C} \mathrm{min}{ }^{-1}$ to $220{ }^{\circ} \mathrm{C}, 16 \mathrm{~min}, 5^{\circ}$ $\mathrm{C} \min ^{-1}$ to $235^{\circ} \mathrm{C}, 7 \mathrm{~min}, 5^{\circ} \mathrm{C} \min ^{-1}$ to $330^{\circ} \mathrm{C}, 1 \mathrm{~min}$.

\subsection{Quality assurance/quality control and statistical analysis}

A breakthrough test that involved adding half of a PUF cartridge in series after the first PUF was performed and no breakthrough was found after a $24 \mathrm{~h}$ sampling period. Field blanks and laboratory blanks were routinely analyzed for quality control. The limit of detection (LOD) was defined as the concentration giving a signal/noise ratio of 3. A PCDD/F concentration below LOD was assigned a concentration of half the LOD. The sample recoveries of the 2,3,7,8-substituted PCDD/Fs ranged $48-103 \%$, which met the limits of US EPA method (SI Table S1). In this study, toxic equivalents (TEQs) for the 17 PCDD/Fs were calculated using international toxic equivalence factors (Kutz et al., 1990). The Shapiro-Wilk test was used for verifying the normality of data. Since concentration values were not normally distributed, the Mann-Whitney $U$ test was used for comparing two data sets (Ssebugere et al., 2014a; Ssebugere et al., 2014b). The comparisons of particle and PCDD/F concentrations during normal days and haze days were tested using this method. To explore the PCDD/F distributions in different particle size fractions, linear correlation analysis was used to explore the relationship between the gas-particle partition coefficient and subcooled liquid vapor pressure (Lee et al., 2008; Li et al., 2008). The levels of significance were set at the $95 \%$ confidence interval $(p=0.05)$. SPSS 22.0 , Origin 8.5, and Excel 2013 were used for data analysis.

\section{Results and discussion}

It was found that $\mathrm{O}_{3}$ concentrations were negatively related to $\mathrm{PCDD} / \mathrm{F}$ concentrations, while concentrations of $\mathrm{NO}_{\mathrm{x}}$ presented the positive correlation trend. (SI Fig. S1). Therefore, $\mathrm{O}_{3}$ and $\mathrm{NO}_{\mathrm{x}}$ concentrations could be used to qualitatively reflect PCDD/F concentrations, although other factors are known affect actual PCDD/F concentrations (Lee et 
al., 2008). The particle and PCDD/F concentrations are presented in SI Tables S2 and S3, respectively. The particle concentrations ranged 236-466 $\mu \mathrm{g} \mathrm{m}^{-3}$ and $117-159 \mu \mathrm{g} \mathrm{m}^{-3}$ during haze and normal days, respectively. The particle concentrations increased as the particle size decreased. Although the particle concentrations varied during haze days and normal days, the particle size distributions were similar. Fine particles $\left(d_{\mathrm{ae}}<2.5 \mu \mathrm{m}\right)$ were dominant during haze days (80\%) and normal days (75\%). PCDD/F concentrations during haze days and normal days were $3979-74,702 \mathrm{fg} \mathrm{m}^{-3}\left(173-3885 \mathrm{fg} \mathrm{I}^{-T E Q ~ \mathrm{~m}^{-3}}\right.$ ) and 988$2846 \mathrm{fg} \mathrm{m}^{-3}$ (173-3885 fg I-TEQ $\mathrm{m}^{-3}$ ), respectively (Fig. 1). It was found that the particle (Mann-Whitney $U$ test, $p<0.05$ ) and PCDD/F concentrations (Mann-Whitney $U$ test, $p<0.05$ ) were significantly lower during normal days. The results indicated that residents in the study area were exposed to relatively high particle and PCDD/F concentrations during haze days. It was noted that more than $98 \%$ of the PCDD/Fs were associated with particles during haze days, whereas $56-95 \%$ of the PCDD/Fs were associated with particles during normal days. The higher chlorinated PCDD/Fs contributed more than the lower chlorinated PCDD/Fs to the total PCDD/F concentrations, with octachlorodibenzo-p-dioxin and octachlorodibenzofuran contributing 23-38\% and 1,2,3,4,6,7,8-heptachlorodibenzo-p-dioxin and 1,2,3,4,6,7,8-heptachlorodibenzofuran contributing up to $27-34 \%$. $2,3,4,7,8$-Pentachlorodibenzofuran was the dominant contributor (26-38\%) to the total TEQs. These observations were consistent with the distribution characteristics during normal days.

The gas-particle partitioning of the $17 \mathrm{PCDD} / \mathrm{F}$ congeners during haze days and normal days were investigated (Fig. 2). Most of the PCDD/F congeners were predominantly $(>90 \%)$ in the particle phase on haze days, with only $20 \%$ of the 2,3,7,8-tetrachlorodibenzo-p-dioxins and dibenzofurans being in the gas phase, which was different than the
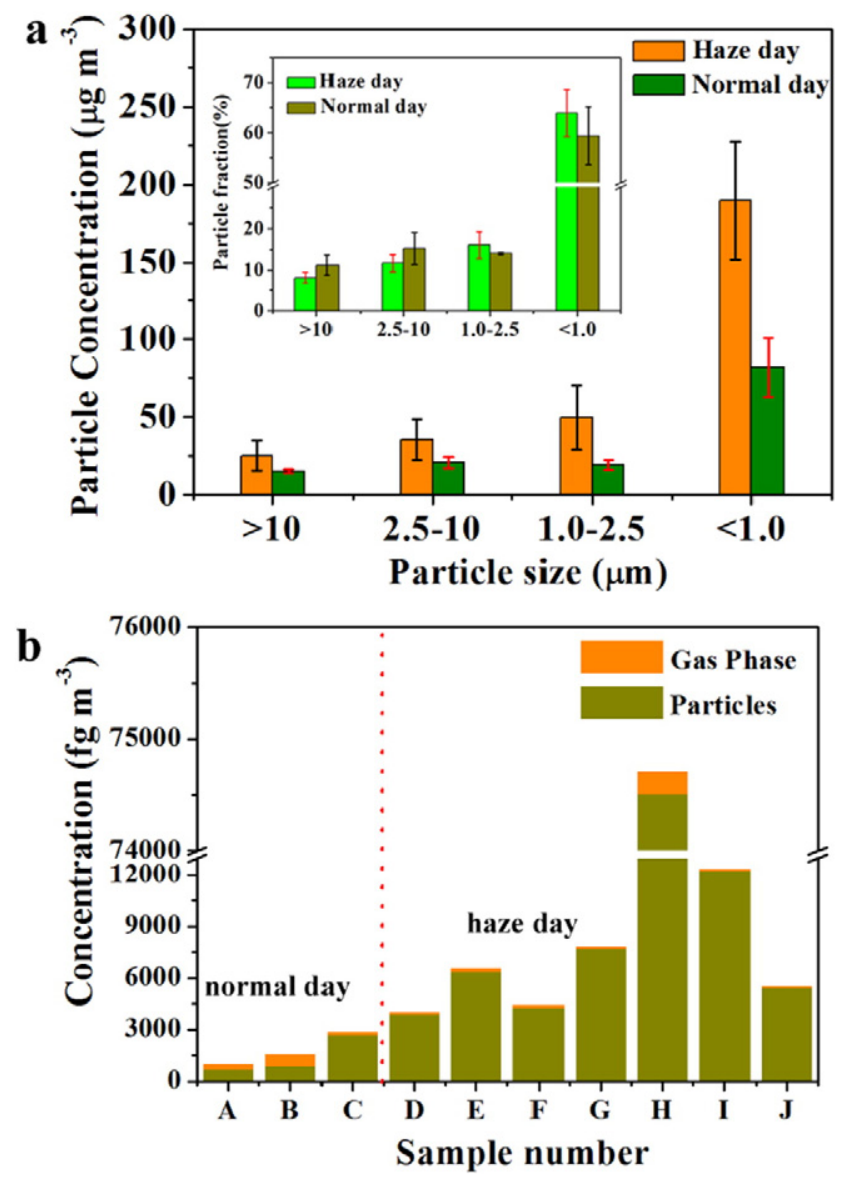

Fig. 1. (a) Size distributions of the airborne particles during haze days and normal days and (b) PCDD/F concentrations in the gas and particle phases of the air samples.
PCDD/F distributions during normal days. The mean particle concentration was two times higher during haze days than normal days, but the PCDD/F congener gas-particle partitioning fractions did not show the same pattern. This may indicate that the PCDD/Fs had different concentration distributions and gas-particle partitioning for different particle sizes during haze days and normal days.

The majority (98\%) of PCDD/Fs were bound to particles. The particulate-bound $\mathrm{PCDD} / \mathrm{F}$ fractions in each particle size fraction during haze days and normal days were also investigated (Fig. 2). During haze days, the PCDD/Fs were predominantly $(80 \%)$ associated with fine particles $\left(d_{\mathrm{ae}}<1.0 \mu \mathrm{m}\right)$ and only a small fraction $(\sim 1 \%)$ were associated with coarse particles $\left(d_{\mathrm{ae}}>10 \mu \mathrm{m}\right)$. The PCDD/F distribution fraction associated with particles increased as the particle size decreased, which was consistent with the results during normal days and previous studies (Degrendele et al., 2014; Hung et al., 2002). The distribution fractions in the $d_{\mathrm{ae}} 1.0-2.5 \mu \mathrm{m}$ particles were similar during haze days and normal days, with both contributing $15 \%$ of particle-bound PCDD/Fs. The PCDD/F fraction associated with $d_{\mathrm{ae}}<2.5 \mu \mathrm{m}$ particles reached $95 \%$, meaning only $5 \%$ was associated with $d_{\mathrm{ae}}>2.5 \mu \mathrm{m}$ particles. Humans would therefore be exposed to 19 times more PCDD/Fs associated with fine particles $\left(d_{\mathrm{ae}}<2.5 \mu \mathrm{m}\right)$ than with coarse particles during haze days. These results were different during normal days, when humans would be exposed to only seven times more PCDD/Fs associated with fine particles $\left(d_{\mathrm{ae}}<2.5 \mu \mathrm{m}\right)$ than with coarse particles. The risks posed by exposure to PCDD/Fs associated with fine particles, especially during haze weather, should therefore be given more attention. The differences found in the distribution of PCDD/Fs for $d_{\mathrm{ae}}<2.5 \mu \mathrm{m}$ and $d_{\mathrm{ae}}>2.5 \mu \mathrm{m}$ particles indicated that gas-particle partitioning could play a role in determining PCDD/F concentrations associated with particles in suburban air.

The gas-particle partition coefficient, $K_{\mathrm{p}}$, defined in Eq. (1), is generally used to define the gas-particle partitioning of semivolatile organic compounds (Lee et al., 2008).

$K_{\mathrm{pi}}=\left(F_{\mathrm{i}} / P M_{\mathrm{i}}\right) / A$

In Eq. (1), $\mathrm{i}$ is the particle size fraction, $P M$ is the particulate matter concentration $\left(\mu \mathrm{g} \mathrm{m}^{-3}\right), F$ and $A$ are the concentrations $\left(\mathrm{fg} \mathrm{m}^{-3}\right)$ of the compound of interest in the particle and gas phase, respectively.

The relationship between $K_{\mathrm{p}}$ and subcooled liquid vapor pressure $\left(P_{\mathrm{L}}^{0}\right)$ of the compound of interest can be calculated using Eq. (2) (Yamasaki et al., 1982).

$\log K_{\mathrm{p}}=m_{\mathrm{r}} \log P_{\mathrm{L}}^{0}+b_{\mathrm{r}}$

The regression coefficient, $m_{\mathrm{r}}$, will usually approach -1 as partitioning equilibrium is approached (Pankow, 1994). Goss et al. concluded that $m_{\mathrm{r}}$ is an important parameter when determining whether adsorption or absorption is the dominant mechanism involved in gasparticle partitioning (Goss and Schwarzenbach, 1998). The $P_{\mathrm{L}}^{0}$ for the PCDD/F congeners can be calculated using Eq. (3), in which $T$ (SI Table $\mathrm{S} 2)$ and $R I$ are the temperature $(\mathrm{K})$ and the gas chromatographic retention index of the compound of interest, respectively (Donnelly et al., 1987; Hale et al., 1985; Hung et al., 2002).

$\log P_{\mathrm{L}}^{0}=\frac{-1.34(R I)}{T}+1.67 \times 10^{-3}(R I)-\frac{1320}{T}+8.807$

The PCDD/F distributions in fine particles $\left(d_{\mathrm{ae}}<2.5 \mu \mathrm{m}\right)$ and coarse particles $\left(d_{\mathrm{ae}}>2.5 \mu \mathrm{m}\right)$ during haze and normal days were further explored (Fig. 3). Significant linear correlations $\left(m_{\mathrm{r}}=-0.60, R^{2}=0.58\right.$, $p<0.001$ for $d_{\mathrm{ae}}<2.5 \mu \mathrm{m} ; m_{\mathrm{r}}=-0.50 R^{2}=0.52, p<0.001$ for $d_{\mathrm{ae}}>2.5 \mu \mathrm{m}$ ) between $K_{\mathrm{P}}$ and $P_{\mathrm{L}}^{0}$ were found during haze days and results indicated that PCDD/Fs were mainly absorbed within particles during haze days. Different results were found during normal days, when the PCDD/Fs associated with $d_{\mathrm{ae}}<2.5 \mu \mathrm{m}$ particles almost approached 
a
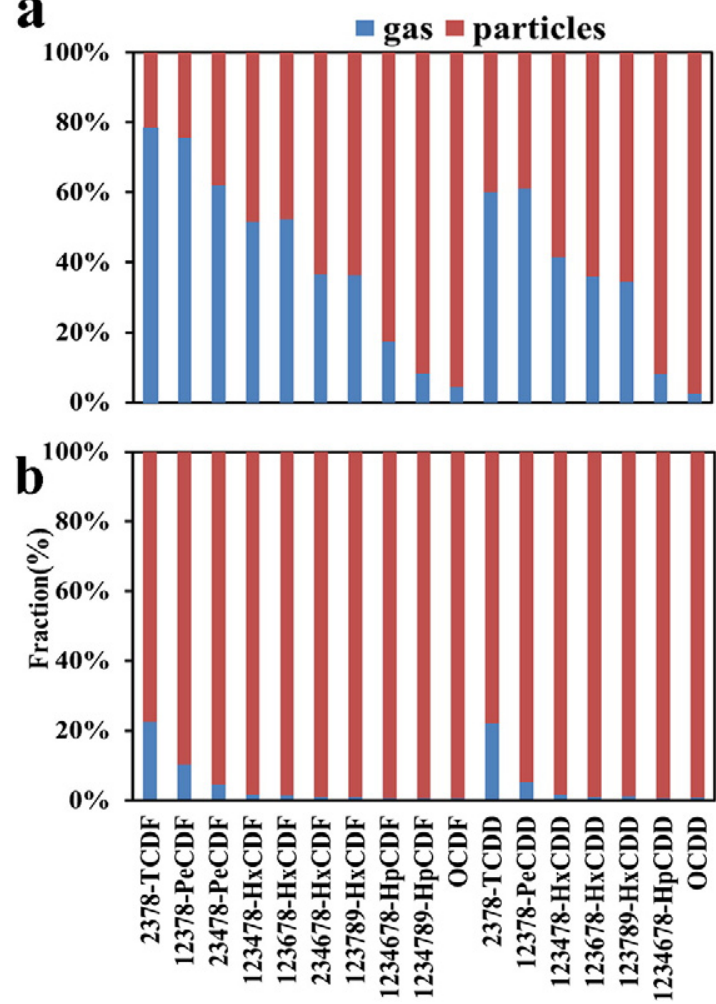
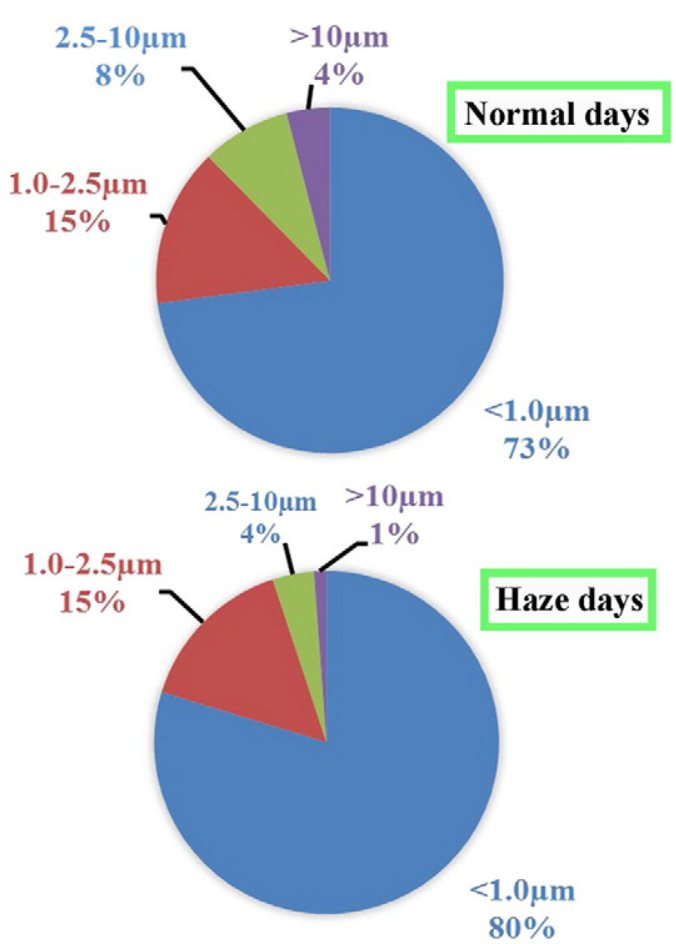

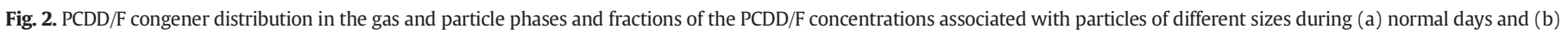
haze days.

gas-particle partitioning equilibrium $\left(m_{\mathrm{r}}=-1.09, R^{2}=0.70\right.$, $p<0.001$ ) and were adsorbed onto the particles. A mixed (adsorption or absorption) sorption model was found for the partitioning of PCDD/ Fs associated with $d_{\mathrm{ae}}>2.5 \mu \mathrm{m}$ particles during normal days, giving a gradient of $-0.82\left(R^{2}=0.63, p<0.001\right)$ (Goss and Schwarzenbach, 1998; Li et al., 2008). The distributions of PCDD/Fs in different particle size fractions $\left(d_{\mathrm{ae}} \mathrm{s}>10,2.5-10,1.0-2.5\right.$, and $\left.<1.0 \mu \mathrm{m}\right)$ during normal and haze days were also further studied. Significant linear correlations between $K_{\mathrm{P}}$ and $P_{\mathrm{L}}^{0}$ were found in each particle size fraction during haze days and normal days (Fig. 4). The slope $\left(m_{\mathrm{r}}=-1.12, R^{2}=\right.$ $0.70, p<0.001$ ) indicated that PCDD/Fs mainly adsorbed onto $d_{\mathrm{ae}}<1.0 \mu \mathrm{m}$ particles during normal days, whereas PCDD/Fs
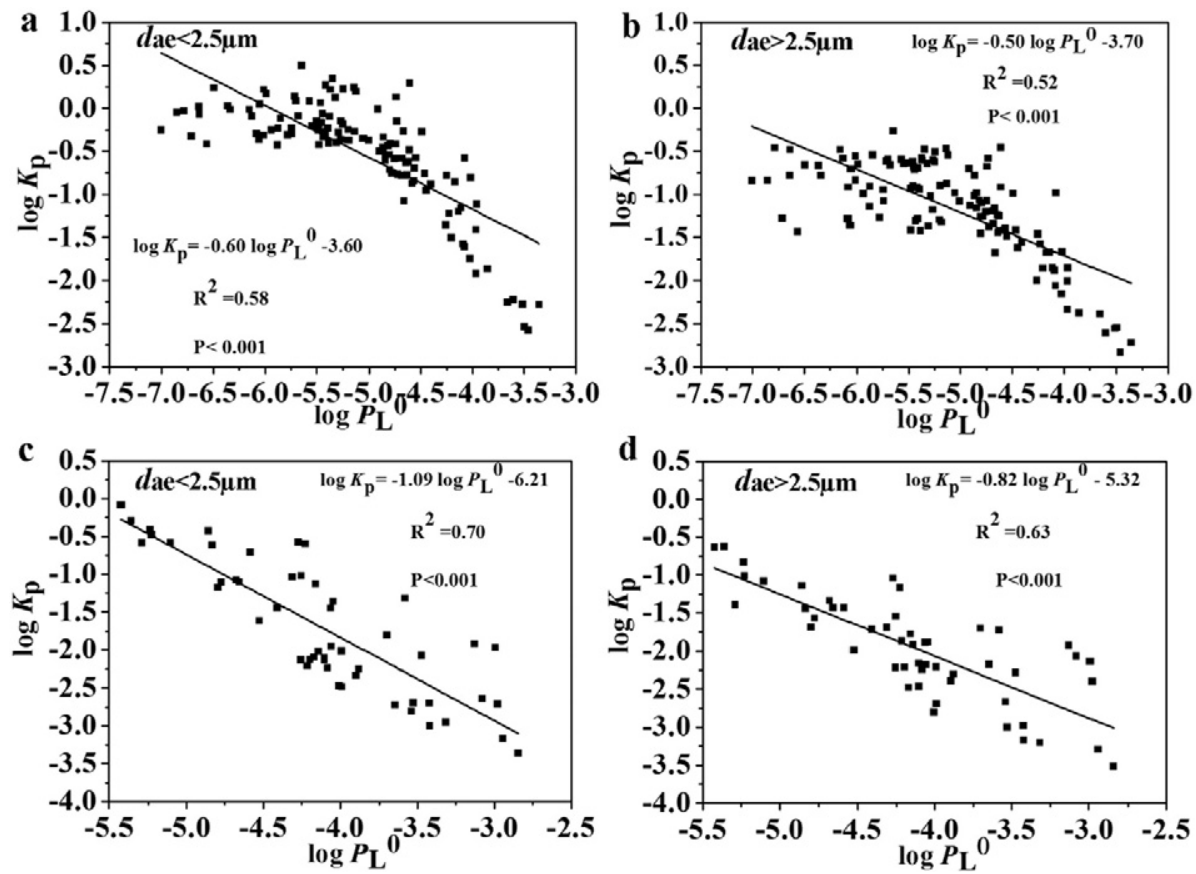

Fig. 3. Measured $\log K_{\mathrm{P}}$ values plotted against the $\log P_{\mathrm{L}}^{0}$ values for PCDD/Fs in $d_{\mathrm{ae}}>2.5 \mu \mathrm{m}$ and $d_{\mathrm{ae}}<2.5 \mu \mathrm{m}$ particle size fractions during (a)-(b) haze days and (c)-(d) normal days. 

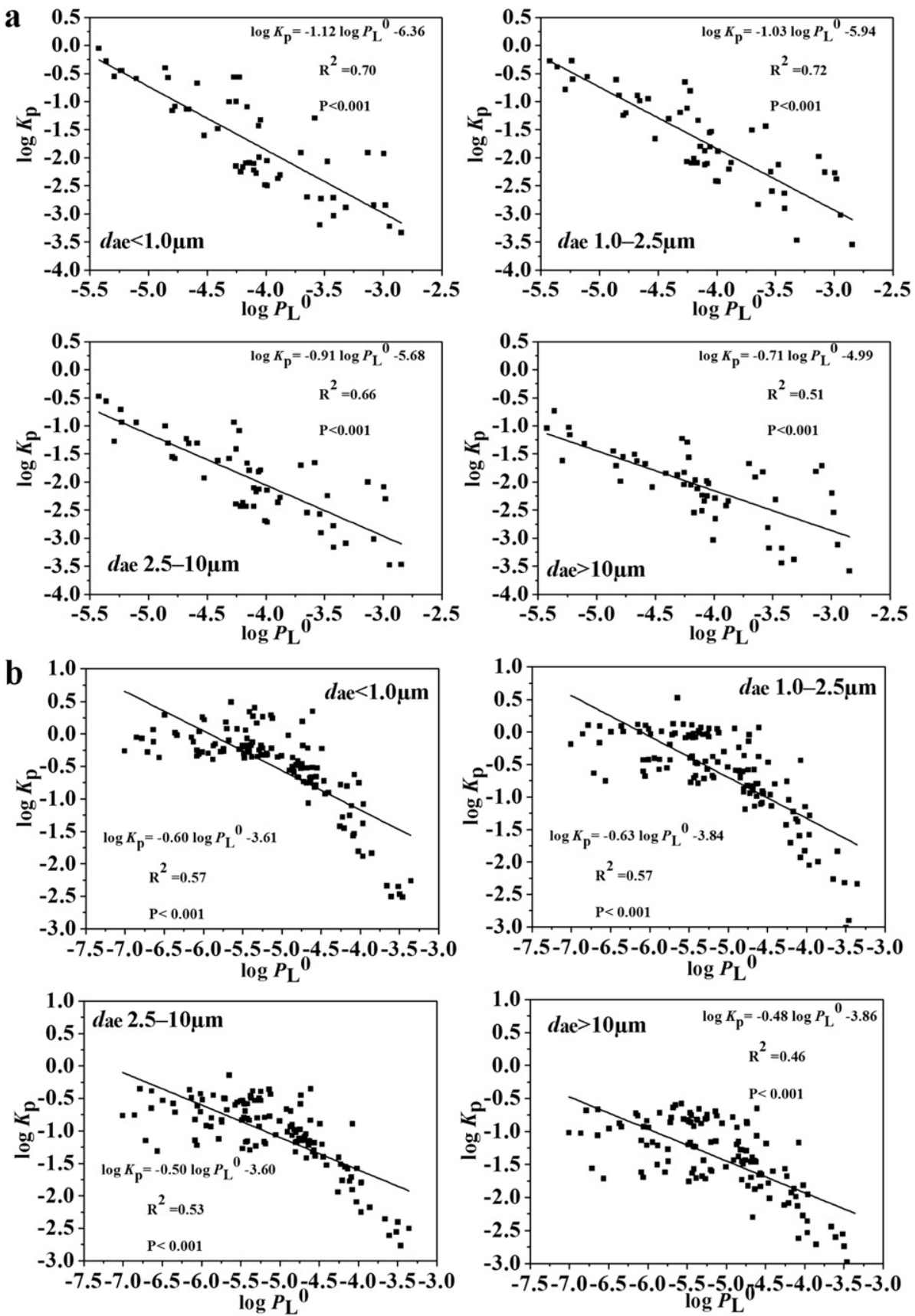

Fig. 4. Measured $\log K_{\mathrm{P}}$ values plotted against the $\log P_{\mathrm{L}}^{0}$ values for PCDD/Fs in different particle size fractions during (a) normal days and (b) haze days.

$\left(m_{\mathrm{r}}=-0.60, R^{2}=0.57, p<0.001\right)$ were absorbed by particles during haze days. As particle size increased $\left(d_{\mathrm{ae}}>2.5 \mu \mathrm{m}\right)$, the $m_{\mathrm{r}}$ values $(-0.90,-0.71)$ ranged between -0.6 and $<-1$, indicating the distributions changed to a mixed sorption model. This was not the same during haze days.

The Junge-Pankow model has previously been found to underestimate or overestimate PCDD/F gas-particle partitioning fractions, and the Harner-Bidleman absorption model was found to better predict PCDD/F gas-particle partitioning (Harner and Bidleman, 1998; Lee and Jones, 1999; Li et al., 2008). Therefore, the Harner-Bidleman absorption model was used to describe gas-particle partitioning of airborne PCDD/ F congeners in this work (Harner and Bidleman, 1998; Xu et al., 2009).

$\varphi=\frac{K_{\mathrm{p}} P M_{\mathrm{i}}}{1+K_{\mathrm{p}} P M_{\mathrm{i}}}$ $\log K_{\mathrm{p}}=\log K_{\mathrm{oa}}+\log f_{\text {om }}-11.91$

In this model, the fraction partitioned onto particles $(\varphi)$ is calculated from $K_{\mathrm{p}}$ and $P M_{\mathrm{i}}$ using Eqs. (4) and (5). The octanol-air partition coefficients ( $K_{\mathrm{oa}}$ values) of the PCDD/F congeners correlate with the temperature $(\mathrm{K})$ and the gas chromatographic retention indices of the congeners (as described in the SI) (Harner et al., 2000). The chemical analyses we used required complete samples to be extracted, so we were unable to determine organic matter concentrations in the samples. The empirical organic matter fractions $f_{\text {oms }}$ of $10 \%, 20 \%$, and $30 \%$ were used instead. The curves presented in Fig. 5 show that the estimated $\varphi$ fit the measured data well during haze days, especially for particles with $d_{\mathrm{ae}}<2.5 \mu \mathrm{m}$. There were some differences between the estimated and measured data for the lower chlorinated PCDD/F congeners (e.g., 


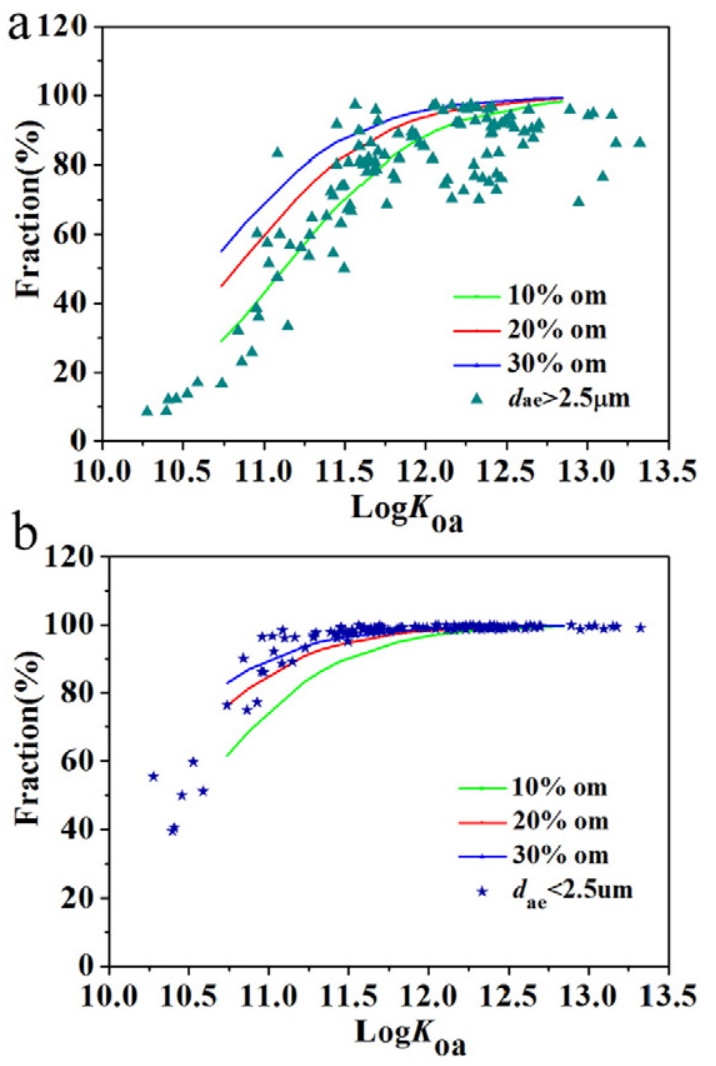

Fig. 5. Measured partitioning fractions for the particles with (a) $d_{\mathrm{ae}}>2.5 \mu \mathrm{m}$ and (b) $d_{\mathrm{ae}}<2.5 \mu \mathrm{m}$ during haze days and partitioning fractions predicted using the HarnerBidleman model using an organic matter (om) content of $10 \%, 20 \%$, or $30 \%$.

congeners with $\left.\log K_{\mathrm{oa}}<11.5\right)$. For particles with $d_{\mathrm{ae}}>2.5 \mu \mathrm{m}$, the data calculated using $f_{\mathrm{om}}=10 \%$ fit the measured data well. The data calculated using $f_{\text {om }}>10 \%$ fit the measured data for particles with $d_{\mathrm{ae}}<2.5 \mu \mathrm{m}$ well. The Harner-Bidleman model did not fit the measured data for normal days (SI Fig. S2). This may be because unsuitable $f_{\text {om }}$ values were used. Overall, the Harner-Bidleman model predicted the particulate fractions of $\mathrm{PCDD} / \mathrm{Fs}$ at the study site reasonably well during haze events.

\section{Conclusions}

Higher concentrations of particles and PCDD/Fs in the atmosphere during haze days than those during normal days were found. PCDD/Fs were predominantly found in the $d_{\mathrm{ae}}<1.0 \mu \mathrm{m}$ particle size fraction and higher concentrations and distribution fractions of PCDD/Fs associated with different sizes of particles were found in the $d_{\mathrm{ae}}<2.5 \mu \mathrm{m}$ particle size fraction. PCDD/Fs were mainly (95\%) absorbed by $d_{\mathrm{ae}}<2.5 \mu \mathrm{m}$ particles during haze days, while they adsorbed onto particles during normal days. The Harner-Bidleman model predicted the particulate fractions of airborne PCDD/F congeners during haze days well, but did not perform well for normal days.

\section{Conflict of interest}

The authors declare no competing financial interest.

\section{Acknowledgments}

The authors thank the Beijing Urban Ecosystem Research Station for supplying basic meteorological data. This work was supported by the National 973 Program (2015CB453100), the Strategic Priority Research Program of the Chinese Academy of Sciences (XDB14020000) and the
National Natural Science Foundation of China (21361140359, 91543108, 21321004, and 21577148).

\section{Appendix A. Supplementary data}

Supplementary data to this article can be found online at http://dx. doi.org/10.1016/j.scitotenv.2016.08.198.

\section{References}

Balasubramani, A., Rifai, H.S., 2015. Occurrence and distribution of polychlorinated dibenzo-p-dioxins and polychlorinated dibenzofurans (PCDD/Fs) in industrial and domestic sewage sludge. Environ. Sci. Pollut. R 22 (19), 14801-14808.

Chandra Suryani, R., Lee, W.J., Endah Mutiara, M., Mwangi, J.K., Wang, L.C., Lin, N.H., et al., 2015. Atmospheric deposition of polychlorinated dibenzo-p-dioxins and dibenzofurans at coastal and high mountain areas in Taiwan. Aerosol Air Qual. Res. 15 (4), 1390-1411.

Chao, M.R., Hu, C.W., Ma, H.W., Chang-Chien, G.P., Lee, W.J., Chang, L.W., et al., 2003. Size distribution of particle-bound polychlorinated dibenzo-p-dioxins and dibenzofurans in the ambient air of a municipal incinerator. Atmos. Environ. 37 (35), 4945-4954.

Chi, K.H., Liu, K.T., Chang, S.H., Chang, M.B., 2009. Atmospheric deposition of PCDD/Fs measured via automated and traditional samplers in Northern Taiwan. Chemosphere 77 (9), 1184-1190

Correa, O., Rifai, H., Raun, L., Suarez, M., Koenig, L., 2004. Concentrations and vapor-particle partitioning of polychlorinated dibenzo-p-dioxins and dibenzofurans in ambient air of Houston, TX. Atmos. Environ. 38 (39), 6687-6699.

Degrendele, C., Okonski, K., Melymuk, L., Landlová, L., Kukučka, P., Čupr, P., et al., 2014. Size specific distribution of the atmospheric particulate PCDD/Fs, dl-PCBs and PAHs on a seasonal scale: implications for cancer risks from inhalation. Atmos. Environ. 98, 410-416.

Donnelly, J.R., Munslow, W.D., Mitchum, R.K., Sovocool, G.W., 1987. Correlation of structure with retention index for chlorinated dibenzo-p-dioxins. J. Chromatogr. A 392, 51-63.

Fiedler, H., Hutzinger, O., Timms, C.W., 1990. Dioxins: sources of environmental load and human exposure. Toxicol. Environ. Chem. 29 (3), 157-234.

Goss, K.-U., Schwarzenbach, R.P., 1998. Gas/solid and gas/liquid partitioning of organic compounds: critical evaluation of the interpretation of equilibrium constants. Environ. Sci. Technol. 32 (14), 2025-2032.

Hale, M.D., Hileman, F.D., Mazer, T., Shell, T.L., Noble, R.W., Brooks, J.J., 1985. Mathematical modeling of temperature programmed capillary gas chromatographic retention indexes for polychlorinated dibenzofurans. Anal. Chem. 57 (3), 640-648.

Harner, T., Bidleman, T.F., 1998. Octanol-air partition coefficient for describing particle/gas partitioning of aromatic compounds in urban air. Environ. Sci. Technol. 32 (10), 1494-1502.

Harner, T., Green, N.J., Jones, K.C., 2000. Measurements of octanol-air partition coefficients for PCDD/Fs: a tool in assessing air-soil equilibrium status. Environ. Sci. Technol. 34 (15), 3109-3114.

Hung, H., Blanchard, P., Poole, G., Thibert, B., Chiu, C.H., 2002. Measurement of particlebound polychlorinated dibenzo-p-dioxins and dibenzofurans (PCDD/Fs) in Arctic air at Alert, Nunavut, Canada. Atmos. Environ. 36 (6), 1041-1050.

In, H.J., Park, S.U., 2003. The soil particle size dependent emission parameterization for an Asian dust (Yellow Sand) observed in Korea in April 2002. Atmos. Environ. 37 (33), 4625-4636.

Kaupp, H., McLachlan, M.S., 2000. Distribution of polychlorinated dibenzo-p-dioxins and dibenzofurans (PCDD/Fs) and polycyclic aromatic hydrocarbons (PAHs) within the full size range of atmospheric particles. Atmos. Environ. 34 (1), $73-83$.

Kutz, F.W. Barnes, D.G. Bottimore, D.P. Greim, H., Bretthauer, E.W. 1990. The international toxicity equivalency factor (I-TEF) method of risk assessment for complex mixtures of dioxins and related compounds. Chemosphere 20 (7), 751-757.

Lee, R.G., Jones, K.C., 1999. Gas-particle partitioning of atmospheric PCDD/Fs: measurements and observations on modeling. Environ. Sci. Technol. 33 (20), 3596-3604.

Lee, S.J., Ale, D., Chang, Y.S., Oh, J.E., Shin, S.K., 2008. Seasonal and particle size-dependent variations in gas/particle partitioning of PCDD/Fs. Environ. Pollut. 153 (1), 215-222.

Li, Y., Jiang, G., Wang, Y., Cai, Z., Zhang, Q., 2008. Concentrations, profiles and gas-particle partitioning of polychlorinated dibenzo-p-dioxins and dibenzofurans in the ambient air of Beijing, China. Atmos. Environ. 42 (9), 2037-2047.

Lin, Y., Huang, K., Zhuang, G., Fu, J.S., Wang, Q., Liu, T., et al., 2014. A multi-year evolution of aerosol chemistry impacting visibility and haze formation over an Eastern Asia megacity, Shanghai. Atmos. Environ. 92, 76-86.

Liu, G., Zheng, M., Ba, T., Liu, W., Guo, L., 2009. A preliminary investigation on emission of polychlorinated dibenzo- $p$-dioxins/dibenzofurans and dioxin-like polychlorinated biphenyls from coke plants in China. Chemosphere 75 (5), 692-695.

Lohmann, R., Lee, R.G., Green, N.J., Jones, K.C., 2000. Gas-particle partitioning of PCDD/Fs in daily air samples. Atmos. Environ. 34 (16), 2529-2537.

Martínez, K., Abad, E., Gustems, L., Manich, A., Gómez, R., Guinart, X., et al., 2006. PCDD/Fs in ambient air: TSP and $\mathrm{PM}_{10}$ sampler comparison. Atmos. Environ. 40 (3), 567-573.

Neugebauer, J., Wittsiepe, J., Kasper-Sonnenberg, M., Schöneck, N., Schölmerich, A., Wilhelm, M., 2015. The influence of low level pre- and perinatal exposure to PCDD/ Fs, PCBs, and lead on attention performance and attention-related behavior among German school-aged children: results from the Duisburg Birth Cohort Study. Int. J. Hyg. Environ. Health 218 (1), 153-162. 
Oh, J.E., Chang, Y.S., Kim, E.J., Lee, D.W., 2002. Distribution of polychlorinated dibenzo-pdioxins and dibenzofurans (PCDD/Fs) in different sizes of airborne particles. Atmos. Environ. 36 (32), 5109-5117.

Ohta, S., Nakao, T., Nishimura, H., Okumura, T., Aozasa, O., Miyata, H., 2002. Contamination levels of PBDEs, TBBPA, PCDDs/DFs, PBDDs/DFs and PXDDs/DFs in the environment of Japan. Organohalogen Compd. 57, 57-60.

Pankow, J.F., 1994. An absorption model of gas/particle partitioning of organic compounds in the atmosphere. Atmos. Environ. 28 (2), 185-188.

Schecter, A., Birnbaum, L., Ryan, J.J., Constable, J.D., 2006. Dioxins: an overview. Environ. Res. 101 (3), 419-428.

Ssebugere, P., Sillanpaa, M., Kiremire, B.T., Kasozi, G.N., Wang, P., Sojinu, S.O., et al., 2014a. Polychlorinated biphenyls and hexachlorocyclohexanes in sediments and fish species from the Napoleon Gulf of Lake Victoria, Uganda. Sci. Total Environ. 481, 55-60.

Ssebugere, P., Sillanpaa, M., Wang, P., Li, Y., Kiremire, B.T., Kasozi, G.N., et al., 2014b. Polychlorinated dibenzo-p-dioxins, polychlorinated dibenzofurans and polybrominated diphenyl ethers in sediments and fish species from the Murchison Bay of Lake Victoria, Uganda. Sci. Total Environ. 500, 1-10.

Tang, Z., Huang, Q., Yang, Y., 2013. PCDD/Fs in fly ash from waste incineration in China: a need for effective risk management. Environ. Sci. Technol. 47 (11), 5520-5521.
Thuan, N.T., Chi, K.H., Wang, S.H., Chang, M.B., Lin, N.H., Sheu, G.R., et al., 2013. Atmospheric PCDD/F measurement in Taiwan and Southeast Asia during Dongsha experiment. Atmos. Environ. 78, 195-202.

Vilavert, L., Nadal, M., Schuhmacher, M., Domingo, J.L., 2014. Seasonal surveillance of airborne PCDD/Fs, PCBs and PCNs using passive samplers to assess human health risks. Sci. Total Environ. 466-467, 733-740.

Xu, M.X., Yan, J.H., Lu, S.Y., Li, X.D., Chen, T., Ni, M.J., et al., 2009. Gas/particle partitioning of atmospheric PCDD/Fs in a satellite town in Eastern China. Chemosphere 76 (11) 1540-1549.

Yamasaki, H., Kuwata, K., Miyamoto, H., 1982. Effects of ambient temperature on aspects of airborne polycyclic aromatic hydrocarbons. Environ. Sci. Technol. 16 (4), 189-194.

Zhang, X., Zhu, Q.Q., Dong, S.J., Zhang, H.X., Wang, X.K., Wang, M., et al., 2015. Particle size distributions of PCDD/Fs and PBDD/Fs in ambient air in a suburban area in Beijing, China. Aerosol Air Qual. Res. 15 (5), 1933-1943.

Zhou, ZG. Zhao, B, Qi, L, Xu, PJ., Ren, Y., Li, N., et al., 2014. Distribution of polychlorinated dibenzo-p-dioxins and dibenzofurans in the atmosphere of Beijing, China. Aerosol Air Qual. Res. 14 (4), 1269-1278. 